\title{
Die Betekenis van die Vel vir Verskillende Fisioterapeutiese Metodes, veral vir Massage
}

\author{
(Verslag van 'n reeks artikels in die „Nederlands Tijdschrift \\ voor Fysiotherapie" van April 1966-Januarie 1967 van die \\ hand van Dr. P. Dethmers, dermatoloog.)
}

Die vel

Die struktuur en funksies van die vel is vir die fisioterapeut baie belangrik omdat die vel die aangrypingspunt van die meeste fisioterapeutiese behandelingsmetodes is.

Die vel is die grootste orgaan van die liggaam, met 'n totaalgewig van $\pm 5 \mathrm{~kg}$ en ' $\mathrm{n}$ totaloppervlak van $1 \frac{1}{2}-2 \mathrm{~m}^{2}$. Die vel bestaan uit:

(a) Epidermis

(b) Dermis of corium

(c) Subcutis

Epidermis

Ontwikkel uit ectoderm en bestaan uit epiteelselle. Dikste in handpalm en voetsool. Dit het nie bloed- en limfvate nie. Epidermis bestaan uit vyf lae en wel van binne na buite:

1. Stratum cylindricum (basaallaag) ) stratum germinati-

2. Stratum spinosum (stekelsellaag) $\} \begin{gathered}\text { vum of } \\ \text { kiemselle-laag }\end{gathered}$

3. Stratum granulosum (korrellaag)

4. Stratum lucidum (heldere laag)

5. Stratum corneum (horinglaag)

Die dermis steek orals met papille, ens. in die epidermis in, wat aan die vel 'n relief gee wat vir elke mens verskillend is en veral aan die vingertoppe te sien is (daktiloskopie).

Stratum cylindricum

Hierdie laag lê op 'n bindweefselige basaalmembraan van die dermis en bestaan uit silindriese selle met 'n kern, watter selle met ,wortelvoetjies" in die membraan geanker is. Van hieruit gebeur die groei en vervanging van die epidermis.

In die ,wortelvoetjies" verloop daar tonofibrille (versterkingsdrade) in bepaalde rigtings (ooreenstemmend met plaaslike trekspanninge), watter fibrille ook deur' die selle van die ander lae verloop en waar hulle net op die selgrense onderbreek word deur protoplasmabruggies (knope van Bizzozero), waar die selmembrane deur kleefstof aan mekaar verbind is. Hierdie knope speel vermoedelik 'n rol by prikkeloordrag van een sel na 'n ander. In hierdie laag lê ook interstisiêle selle, die melanodendrosiete van Riehl (,clearcell"), wat met hulle vertakte uitlopers tot in die stratum spinosum strek. Hierdie selle is pigmentvormend. Stratum spinosum

Dit bestaan uit poliêdriese (veelvlakkige), onreêlmatige selle met 'n kern.

Hierdie selle is weer met mekaar verbind deur baie protoplasmabruggies (knope van Bizzozero), waardeur die selle op deursnit stekelvormig lyk. Ook hier weer tonofibrille, onderbreek in bogenoemde knope. Hierdie laag neem ook deel aan groei en vervanging van die epidermis. In hierdie laag lê die interstisiêle selle van Langerhans, wat aktief nerveuse selle is en uit die melanodendrosiete ontwikkel het en na onder toe dan ook met hulle in verbinding staan. $\mathrm{Na}$ bo toe vertak hulle boomvorming tot in die stratum granulosum.

\section{Stratum granulosum}

Dit bestaan uit selle wat nog wel 'n kern het, maar wat tog al duidelik afgeplat is en dan ook al horingagtig begin word. In die sitoplasma is daar keratohialienkorrels, 'n voorstadium van die horingstof keratien.

Stratum lucidum

Dit bestaan uit plat selle wat nie meer ' $n$ 'kern het nie. Dit bevat ook keratohialien.
Hierdie laag is slegs in beperkte maat deurlaatbaar en werk dan ook as 'n permeabiliteitsrem teen oormatige waterverlies. Onder die stratum lucidum is die voggehalte van die selle \pm 70 persent en in die stratum corneum is dit nog maar 'n paar persent.

\section{Stratum corneum}

Dit bestaan uit baie plat selle sonder kern, die horingselle. Die keratohialien van die twee vorige lae het oorgegaan in keratien (horingstof). Ook hier is daar in die selle tonofibrille en tussen die selle knope van Bizzozero. Die verlies van selle vanaf die stratum corneum word aangevul vanuit die kiemsellelaag of stratum germinativum.

Die horinglaag is baie belangrik as beskerming vir te veel son en is eintlik die ,sonsambreel vir die vel" (Miescher). Onder invloed van U.V.-lig word die stratum corneum baie dikker.

\section{Dermis of corium}

Dit is eintlik die belangrikste deel van die vel omdat hierdie deel die weerstandvermoè, die elastisiteit en die sensitiwiteit aan die vel gee. Ook die warmte regulasie word vir 'n groot deel gereêl deur die bloed- en limfvate in die dermis. 'n Basaalmembraan skei die dermis van die epidermis. Die dermis het ontwikkel uit die mesoderm.

Die bindweefsel waaruit die dermis opgebou is, bestaan uit kollagene, elastiese en retikulere vesels. Tussen die vesels in lé die selle (bindweefselselle, fagosiete, plasmaselle, limfosiete, mastselle, ens.) waarvan die aantal wissel met die fisiologiese en patologiese toestande van die vel (ontstekings) Hulle lè in 'n vloeibare grondsubstansie op:die samestelling waarvan die mastselle glo invloed uitoefen. Die granulering van die mastselle kan deur meganiese, chemiese, hormonale en aktiniese prikkels beïnvloed word.

Die totale struktuur van die bindweefselvesels bepaal die rekbaarheid en die trekvasheid (trekspanning) van die vel. Ten slotte kom daar in die dermis nog 'n derde soort interstisiêle sel voor, naamlik die selle van Cajal, wat saam met die melanodendrosiete van Riehl en die selle van Langerhans die neuro-hormonale sisteem van die vel vorm.

Die selle van Cajal word veral gevind in en om die gladde spiervesels van bloedvate, kliere en haarspiere (arrectores pilorum). Hulle is van baie groot belang vir die prikkeloordrag op die gladde spiervesels.

Die selle is onderling verbind deur buisvormige protoplasmastringe waarbinne fibrille verloop en kerne van Schwann aanwesig is. Die protoplasmastringe staan aan die een kant in kontak met die bloedvatwande en aan die ander kant met die melanodendrosiete van Riehl in die stratum cylindricum.

\section{Melanogenese (pigmentvorming)}

Dit gebeur in die melanodendrosiete van Riehl. In die sitoplasma van hierdie selle kom daar die aminosuur tirosien voor en dit is die enigste stof waaruit die melanodendrosiete melanien kan maak. Veral onder invloed van die ensien tirosinase $+\mathrm{O}_{2}$ gaan hierdie proses baie vinniger, omdat dan dopa (dioksiphenielalanien) gevorm word en die dopa werk dan as katalisator op bogenoemde proses. Die dopa wat self kleurloos is, word nou onder invloed van die ensien dopa-oksidasie $+\mathrm{O}_{2}$ omgevorm tot dopaortochinon (donkere stof), waaruit uiteindelik melanien ontstaan. 
Pigmentbevorderende prikkels is dan: U.V.-lig, bepaalde intoksikasies (bv. arsenikum), ontstekings, oestrogene stowwe by swangerskap (chloasma gravidarum), ens. Om egter 'n gelykmatige pigmentering van die epidermis te $\mathrm{kry}$, is daar nog ander prosesse nodig, nl. die uitstrooiing en is dafte van die melanienkorrel aan die omliggende weefsels, wat dispersie genoem word.

'n Besondere vorm hiervan is sitokrinie, waar die melanienkorrels spesiaal aan die basaalselle (epiteelselle) in die stratum cylindricum afgegee word om sogenaamde ,poolkappe" te vorm.

Saam met die stratum corneum (sonsambreel) is die funksie van die melanien om 'n beskutting te vorm vir die skadelike inwerking van te intensiewe U.V.-lig op die gevoelige stratum germinativum. Die poolkappe van melanienkorrels beskerm die kerne van hierdie selle (veral langgolwig U.V.-lig groter as $3000 \mathrm{~A}^{\circ}$ ).

By depigmentasie en pigmentsteurnisse soos vitiligo en albinisme mag daar wel of nie melanodendrosiete aanwesig wees, maar in ieder geval produseer hulle te min melanien, dus is daar ' $n$ afwyking in die pigmentstofwisseling.

\section{Die neuro-hormonale sisteem van die vel}

Hierdie sisteem word gevorm deur (1) die interstisiêle selle van Cajal in die dermis (2) die melanodendrosiete van Riehl in die stratum cylindricum en (3) die selle van Langerhans in die stratum spinosum. Hierby vervul die melanodendrosiete van Riehl eintlik die rol van ,skakelstasie”.

Ondersoekers (veral Wiedmann en Niebauer) het gevind dat die neuro-hormonale selle van Cajal in hulle sitoplasma twee soorte granula (korrels) bevat. Die een soort granula bevat noradrenalien, wat ook uit tirosien gemaak word. Die sintese is: Onder invloed van die ensiem tirosinase $+\mathrm{O}_{2}$ word uit tirosien die stof dopa gevorm wat self weer onder invloed van die ensiem dopa-dekarboksilase $+\mathrm{O}_{2}$ omgevorm word tot dopamien, waaruit uiteindelik noradrenalien gevorm word.

Dit blyk dus dat melanien en noradrenalien albei van tirosien afkomstig is.

In die ander soort granula is histamien gebind aan heparien sowel as Adenosien-triphosfaat (A.T.P.). Hierdie histamien word vermoedelik deur sogenaamde "H-bevryders" (,H-liberators") uit die granula vry gemaak, waarby die ensiem A.T. Phosfatase 'n belangrike rol speel.

\section{Prikkeloordrag}

Soos by alle senuwees gebeur die prikkeloordrag by die selle van die neuro-hormonale sisteem ook via sinapse, waarby die mitochondriee 'n belangrike rol speel. Hulle dien as energiebron om die sel te laat funksioneer.

Die mitochondrieẽ vorm blasies wat in die pre-sinaptiese sitoplasma versprei. Die blasies, wat vermoedelik asetielcholien bevat, beweeg nou deur die sinaptiese membraan en gee hulle inhoud af an die post-sinaptiese sitoplasma. Hierdie proses is vermoedelik verantwoordelik vir die prikkeloordrag.

Daar kan vermoedelik by prikkeloordrag tussen twee senuwees twee sisteme onderskei word: Die cholinergiese of histiotrope sisteem (gerig op herstel) met asetielcholien as tussenstof, en die adrenergiese of ergotrope sisteem (gerig op arbeid) met adrenalien of noradrenalien as tussenstof. Die laaste sisteem is egter nog nie bewys nie.

\section{Die mastselle}

Hierdie selle, wat na hulle afstamming tot die retikulēre bindweefsel behoort (mesoderm), word amper in elke orgaan aangetref, maar spesiaal ook in die vel, waar hulle veral perikapillêr voorkom. Hulle is kenbaar deur 'n groot ophoping van granula wat mukopolisakkariede (o.a. haluronsuur, chondroitienswaelsuur en heparien) bevat. In die vel speel die mastselle ' $n$ baie belangrike rol in die bindweefselvorming, dus by regenerasie en reparasie van wonde, omdat die mukopolisakkariede belangrike boustowwe van die bindweefselgrondsubstansie is.

Hierdie grondsubstansie bestaan uit:

1. Mukopolisakkariede (koolhidrate)

2. Proteïne

3. Elektroliete

4. Water

Behalwe die mukopolisakkariede bevat die mastselle ook histamien en serotonien (5-hidroksitriptamien).

Hulle het gevind dat mastselvermeerdering en -aktiwiteit opgewek word deur meganiese wrywing van die vel, dus deur massage (gevind by hamsters deur sterk wrywing van die vel van die wangsakke).

\section{Heparien}

Hierdie stof blokkeer die omsetting van protrombien in trombien en gaan stolling dus teen.

Die mástselle is vermoedelik die produksie- en stoorselle van hierdie stof.

As daar 'n haemartrose ontstaan na 'n trauma, is daar baie mastselle in die sinoviale membraan. Dit verklaar die feit waarom die bloed in die gewrig nie stol nie, maar altyd vloeibaar bly.

\section{Histamien of $\mathrm{H}$-stof}

Histamien is in mastselle veral aan heparien gebind. Die histamien word vrygestel deur „H-bevryders", en het 'n vaatverwydende invloed op die grotere arteriole, terwyl in die kleinere 'n vasokonstriksie ontstaan. Die kapillêre reageer op histamien met verhoogde vasodilatasie en permeabiliteit (o.a. vir proteine wat weer tot uitbreiding van vog lei).

Behalwe histamien word ook heparien en serotonien (5-HT) deur-die „H-bevryders" vrygestel.

\section{Die mukopokisakkariede}

As gevolg van vermeerderde weefselvog (edeem) ontstaan degranulering van die mastselle. Die belangrikste mukopolisakkaried wat hierdeur vrykom, veral die eerste twee dae, is hialuronsuur. Dit het baie sterk waterbindende eienskappe en bind dan ook die vermeerderde vog deur vorming van 'n ,gehidrateerde gel" (hidraat = binding van water; gel $=$ nie vloeibare kolloïdale oplossing). Na die eerste twee dae ontstaan veral chondroitien-swaelsuur (hoof bestanddeel van die bindweefselgrondsubstansie) en 'n vermeerdering van kollageen bindweefsel.

Die mastselle bevat dus stowwe om water te bind (hialuronsuur) en stowwe wat vermeerderde weefselvog ver oorsaak (histamien).

\section{Wondgenesing}

Die mastselle is van baie groot belang by wondgenesing omdat hierdie selle die stowwe vir herstel en groei lewer: Eers kry ons 'n mukineuse organisasie van sereuse edeemvloeistof deur hialuronsuur (eerste twee tot drie dae), wat die voedingsbodem vorm vir die selle en fibrille. Daarna kry ons o.i.v. chondroitienswaelsuur die vorming van die bindweefselgrondsubstansie en kollagene vesels, dus 'n fibreuse organisasie. Hierdie granulasieweefsel bestaan uit jong bindweefselselle of fibroblaste.

Ook by ontstekings word dieselfde patroon gevolg. Die reserwe aan mastselle en die snelheid van mukopolisakkariede-sintese bepaal hierby die doeltreffendheid van die resistensie teen infeksies. 


\section{Mastselle is dus belangrik vir o.a.}

1. Produksie van hialuronsuur en chondroitienswaelsuur en daarom:
(a) Vorming van 'n ,gehidrateerde gel" by edeem.

(b) Mukineuse en fibreuse organisasie by wondgenesing.

(c) Beinvloeding van die bindweefselwaterhuishouding.

(d) Opbou van bindweefsel.

2. Produksie van histamien en daardeur beïnvloeding van alle allergiese prosesse.

3. Produksie en stoor van heparien en daardeur remming van stollingsmeganisme.

4. Produksie van serotonien:

(a) Gee kontraksie van gladde spierweefsel.

(b) Veroorsaak pyn deur prikkeling van senuweeuiteindes (bv. by ontstekings).

\section{Die pynmeganisme}

Pyn is 'n gevoelsreaksie op 'n skadelike prikkel waarvan in die vel, as beskermingsorgaan, die grootste persepsie plaasvind. Vir pynsensasie is daar nie eintlik spesiale reseptore nie soos vir tas (Meissner), warmte (Ruffini) of koue (eindkolfies van Krause), maar daar word aangeneem dat die vrye senuwee-uiteinde tussen die epiteelselle hiervoor aanspreeklik is. In die verband kan ons o.a. noem die boomvormige eindvertakkings van die selle van Langerhans tot onder en in die stratum granulosum.

Die pyn is vermoedelik nie 'n direkte prikkelpersepsie van die senuwee-uiteindes nie, maar as gevolg van die pynprikkel word daar in die weefsel stowwe gevorm wat indirek die prikkel op nerveuse elemente oorbring.

Bekende pynstowwe is dan o.a.: $\mathrm{K}$-ion, suurgraad $(\mathrm{pH})$, asetielcholien, histamien, serotonien (5-H.T.), verskillende soorte kinien en P.V.S. (Pyn Veroorsakende Stof) wat almal gedek word deur die versamelnaam ,neurokinien).

Die K-ion en suurgraad werk meer direk, terwyl die ander stowwe vermoedelik nie self pyn opwek nie, maar wel die pyndrempel verlaag en die bepaalde area daardeur oorgevoelig vir pyn maak. Hierdie pynverwekkende stowwe kan orals in die liggaam ontstaan, maar veral in die vel. (Kontrairritasie by die behandeling van diep pyn!)

\section{Juk en pyn}

Juk kan in die vel opgewek word deur 'n chemiese prikkel wat vermoedelik nie net 'n pyn onder die drempelwaarde is nie, maar ook 'n afsonderlike gevoelskwaliteit is. Hulle het o.a. gevind dat histamien eerder juk as pyn yeroorsaak.

Die verskil tussen juk en pyn kom al tot uiting in die verskillende reaksies: krapreaksie by juk en terugtrek by pyn.

\section{Die bloedsirkulasie in die vel en allergie}

Die opvattings omtrent hierdie sirkulasie het verander. Vroeêr is gedink dat die algemene sirkulasie oorgaan in 'n min of meer passief kapillêr buisstelsel. Teenswoordig is die opvattings anders: Daar is 'n direkte verbinding tussen arterieel en veneus bloedvatsisteem via die hemodukte van Nelemans (mesarteriole van Zweifach).

Die voedingskapillère ontvang hulle bloed nou vanaf hierdie hemodukte en vanuit die kapillêre word die voeding van die weefsel versorg (interstisiêle vogstroom wat $\mathrm{O}_{2}$ en voedingstowwe aanvoer en afvalprodukte afvoer).

Behalwe die hemodukte is daar verder arterio-veneuse verbindings (a.v. bridges of anastomosen), wat 'n kortsluiting tussen die arteries en venes tot stand bring. Bloed wat deur hierdie anastomoses gaan, neem egter nie deel aan die voeding van die weefsels nie, maar bring 'n deel van die vis a tergo (stukrag) van die hart direk oor van die arteriêle na die veneuse bloedvate. Verder het die anastomoses 'n afsuigende werking op die bloed in die klein venes. Die hoeveelheid vog wat in 24 uur die bloedbaan verlaat, in die weefsels sirkuleer en weer in die bloedbaan terugkom, is 1 000-6 000 liter, afhanklik van die aktiwiteite van die organisme. Hierdie weefselvogdeurstroming staan in noue verband met die weefseldruk, waarby elke orgaan sy eie weefseldruk het waaronder hulle die beste kan funksioneer.

Die kragbronne vir die weefselvogdeurstroming is o.a. die hidrostatiese en kolloïdosmotiese druk in die kapillêre.

Daar word aangeneem dat die kapillère orgaan-eie is en nie tot die algemene bloedvatstelsel behoort nie. In jong granulasieweefsel is aangetoon dat die kapillêre hulle selfstandig ontwikkel en daarna aansluiting soek met die algemene bloedvatstelsel. Daar is nou aanwysings dat die funksies van die weefseleie kapillêre ook versorg word deur 'n weedseleie senuweestelsel (neuro-hormonaalsisteem van die vel).

Die weefselvogdeurstroming staan daarom ook onder invloed van hierdie sisteem en verder van die vis à tergo van die hart en die weerstand van die weefsel self.

By bepaalde patologiese prosesse en ook by allergiese prosesse, tree daar altyd ' $n$ verhoogde spanning (druk) in die betrokke weefsels en organe op met 'n toename van volume. Die verhouding tussen aan- en afvoer van weefselvog is dus versteur.

Bly die verhoogde spanning te lank bestaan, dan tree bindweefselvorming op waarby die mastselle ' $n$ belangrike rol speel omdat hulle hialuronsuur en chondroitienswaelsuur produseer, nodig vir die bindweefselvorming.

Bly die spanning vir 'n lang tyd te laag, dan kry ons verkleining van die weefselvogruimte en atrofie.

Dit is daarom van belang dat die regte weefselstroom en -spanning gehandhaaf word om die weefsels en organe optimaal te laat funksioneer.

Die verskynsels wat by allergieē optree kan amper altyd teruggebring word tot veranderinge in die perifere sirkulasie, veral van die vel maar ook van die slymvliese.

Dit word tans algemeen aanvaar dat by allergiese prosesse, histamien uit mastselle en N.H.-selle vrygestel word en dat die veranderde weefselvogverhoudings vir 'n belangrike deel hieraan toegeskryf moet word.

In die algemeen kan die werking van histamien as volg opgesom word: vaatverwyding en verhoging permeabiliteit kapillêre, dilatasie van grotere en konstriksie van kleinere arteriole, konstriksie van kleinere vene, weefselstroomtoename, toename van kliersekresie en kontraksie van gladde spierweefsel.

Werk die perifere sirkulasie nou baie sleg (bv. by skoktoestande) dan is die werking van histamien ook baie minder en sien ons die teenoorgestelde werking.

Behalwe histamien speel noradrenalien (N.H.-selle) ook 'n rol by die allergiese prosesse. Dit werk sterk vaatvernouend en is dus in die vel die antagonis van histamien.

Saam reēl hulle waarskynlik die bloeddrukewewig. Die een dra sorg dat die ander sy invloed nie te ver uitstrek nie.

\section{Samevatting}

Die bedoeling van die skrywer met hierdie serie artikels is om die invloed en effekte van massage in 'n nuwe lig te sien, met die moontlikheid dat die teorie waarop die massage tot nou toe gebou is, miskien in die toekoms deur andere en meerdere ondersoekings veranderinge sal ondergaan.

Veral die eienskappe en aktiwiteite van die mastselle sal hierin 'n rol speel, maar tog ook die neuro-hormonale sisteem van die vel. Vir 'n goeie begrip van die massage en ander fisioterapeutiese metodes sal dit goed wees om die neuro-hormonale en biochemiese prosesse wat hom in die vel afspeel te leer ken, omdat die vel tog altyd die aangrypingspunt in fisioterapie bly.

B. GOEDHART 